\title{
Changing Trends in Teaching Method for Medical Students-Prosection Versus Dissection of Cadavers
}

\author{
Sudakshina Chakrabarti \\ Assoc Prof of Anatomy, Saveetha Medical College \& Hospiital Chennai
}

\begin{abstract}
Background: Cadaveric dissection is considered a tool for studying structural details of the human body. Prosection is demonstrating anatomy of wet specimens preserved and already dissected by experts. In prosection students get to see multiple wet specimens, museum specimens already dissected by experts and learn by observing the structures.
\end{abstract}

Methodology: Study is conducted on 30, 1st year MBBS students divided randomly into 2 groups each having 15 students-- Group A and Group B. Informed consent is taken from all the participants prior to the study. The second part of study conducted on final year MBBS students on their view on cadaveric dissection

The anatomy of the neck region which extends over 8 hours of dissection classes are taught to the group A by traditional dissection demonstration method. The same is taught to Group B by prosection technique. The following day the performance of the students are assessed by a spot identification test consisting of 15 questions each of 2 marks pertaining to the specimens as a practical test. In the second part of the study feedback is taken in form of a validated questionnaire from final year MBBS students about their view on cadaveric dissection.

Results: The performance of the spot identification test conducted on the students was analysed uniformly and corrected by 2 experts. The results shows the performance of group B (Prosection group) was significantly better than group A (p value 0.034 at $95 \%$ CI). On analysing the feedback majority of final year students liked dissection on cadavers and they felt it promoted group learning and future knowledge on surgical instruments and skills.

Conclusion: This study suggest that utilizing prosections of the neck region specimens seem to be advantageous pedagogical approach for teaching Gross Anatomy. Based on the views on cadaveric dissection of final year studentsit is better toadopt combined approach and expose students to both techniques dissection and prosection.

Keywords-: Prosection, Dissection, demonstration, specimens questionnaire.

\section{Introduction}

A good knowledge of clinical Anatomy is fundamental and indispensable to efficient and safe

\section{Corresponding Author:}

\section{Dr. Sudakshina Chakrabarti}

Appasamy Platina Apartments 7042, Mount

Poonamallee High Road Porur Chennai-6000116

e-mail: sudhianat@gmail.com

Ph. No.: 9840246297 clinical practice and for the understanding of other subject disciplines such as physiology, pathology and surgery for a medical students.

Cadaveric dissection is considered a tool for studying structural details of the human body. Major part of practical working in gross anatomy consists of cadaver dissection by students. This method of learning human gross anatomy is time-honoured and highly effective recent years. Time and again the relevance and value of dissection as a tool for teaching anatomy to medical students have beenunder discussion at different 
occasions. ${ }^{1}$ Due to cultural practices which makes availability of cadavers difficult and also increase in number of students in medical course there is a rapid decline in student cadaver ratio. ${ }^{2}$ The high costs, time intensity, the requirement for highly skilled teachers and the emotionally challenging nature of cadaveric dissection as well as being a cause of significant psychological distress among medical students have been cited as its potential disadvantages of cadaveric dissection. ${ }^{3}$ This has ultimately resulted in using newer techniques to teach Gross Anatomy. Not only the student cadaver ratio is unfavourable there is also a need of completing the syllabus of gross Anatomy in a limited time frame available for first year MBBS. With reduction in contact hours less emphasis being given to the basic science courses in the pre-clinical years of medical education and with the need for integration has resulted in the need for educators in the anatomical sciences to develop new pedagogical approaches which are more time efficient at the same time do not compromise students learning experiences. ${ }^{4}$

Prosection is demonstrating anatomy of wet specimens preserved and already dissected by experts which is being considered as an effective teaching tool in Anatomy for undergraduate medical students. Thus in prosection students get to interact with multiple wet specimens, already dissected by experts and learn by observing the structures. Students working together to learn from prosected materials may spend more time focused on the learning objectives than students dissecting in a team where most of them are just passive observers. Students working with multiple prosected specimens have the opportunity to view several variations, rather than the single variation which may or may not be present in their dissection cadaver. ${ }^{5}$ With the present integrated medical curriculum and less time allotted for basic science subjects there is a need to judiciously manage the time available. Complete dissection of cadaver by first year medical students is time consuming and there no concrete evidence as whether it is required or not for a medical graduate. ${ }^{6}$ Dissection skill is not a required competency for undergraduate medical student as per medical council of India curricular regulation. Not only prosected specimens an increasing number of computer assisted learning tools (CAL) have been introduced to fill in the practical aspects of teaching human anatomy especially for cross sectional anatomy. Newer techniques like plastinated specimens are also being used and used increasingly. ${ }^{7,8,9}$ This study is an attempt to introduce prosection as a regular tool in teaching Anatomy to first year MBBS students as an alternative to cadaveric dissection. This study also assesses the perception of final year medical students on the importance of dissection in learning gross anatomy as a feedback using a validated questionnaire and whether they would prefer dissection.

Objectives: To compare the performance of the students who are taught Gross Anatomy of neck region by dissection versus students taught by prosection method.

To assess the perception of students towards including prosection in regular teaching method in Gross Anatomy.

\section{Material and Method}

Project proposal approval was obtained from Institutional ethical committee in Saveetha Medical College \& Hospital. (SMC/IEC/2019/05/005). Study was conducted in two parts.

30 randomly selected 1 st year MBBS students were divided randomly into 2 groups each group of 15 students Group A and Group B. Informed consent is taken from themafter explaining the study.

Permission to conduct the study was taken from the HOD of Anatomy department and permission of taking help from other teaching staffs was obtained from the head of department.

The anatomy of the neck region which extends over 8 hours of dissection classes was identified which includes a. Midline structures of neck, b. anterior triangle and c. posterior triangle dissection and demonstration. The above regions are taught to the group A by traditional dissection demonstration method. The same regions are taught to Group B through interactions by experts on already dissected preserved wet specimens and museum specimens by prosection technique.

Group B classes are taken in the museum and they were not allowed to dissect for the study period. Classes being taken in respective groups simultaneously is being shown in Fig 4.

Both groups were given an extra of 2 hours for revision of the specimens and at the end of 10 hours of Dissection classes the following day the performance of the students are assessed by a spot identification test consisting of 15 questions each 2 marks pertaining to the 
specimens as a practical test conducted at the end of the session .

Once the study period was over the Group B students were allowed to dissect the neck.

In the second part of the study informed consent was taken from 150 final year medical students of the same college. A validated self framed questionnaire in Likert scale of 10 questions was used to assess the perception of final year MBBS students about cadaveric dissection. Internal validity of the questionnaire was tested using Cronbach's alpha. The total questionnaire Cronbach's alpha value was calculated as 0.613 which is acceptable. Each participant was given 10 minutes to fill the form which was collected back for analysis. The questionnaire is shown in table 3

Performance of the 30 first year MBBS students of Group A and Group B was statistically analysed. The questionnaire collected from the final year students were analysed SPSS version 21 was used to analyze the data.

\section{Results}

The performance of the spot identification test conducted on the first MBBS students Grp A and Grp B was analysed uniformly and corrected by 2 experts. The results are shown in Figure 1.

The Mean score, Median and standard deviation was calculated and plotted in table 1

Difference of mean value between two groups ia 3.00 ,standard error is 1.348 . Applying paired $t$ test it was seen at $95 \%$ confidence interval the $\mathrm{P}$ value obtained is $<0.05$. table 2 and Fig 2 So the difference in the performance of the two groups is significantly better in Group B students taught by prosection technique than group A students taught by cadaveric dissection and demonstration.
The responses of the questionnaire was analysed by percentage and frequency. On analysis of the questionnaire filled by final year MBBS students it was seen they preferred cadaveric dissection. $71 \%$ of students agreed that orientation and consistency of gross structures are better observed in cadaveric dissection. $87 \%$ students felt visual memory of the structures were better after dissection. $77 \%$ of students strongly agreed that dissection helped them to learn how to use basic surgical instruments in future years. $81 \%$ of the students felt dissection promoted group learning and discussion. $90 \%$ of the final year students felt they learnt to respect the dead in dissection hall. Thus cadaveric dissection is favored strongly among final year students. Table $3 \&$ Fig 3.

Table 1: Marks obtained by Group A and group B-analysis.

\begin{tabular}{|l|c|c|}
\hline & Group A & Group B \\
\hline Mean & 18.26 & 21.26 \\
\hline Median & 18 & 22 \\
\hline Mode & 18 & 24 \\
\hline Standard deviation & 4.25 & 3.03 \\
\hline
\end{tabular}

Table 2: Statistical analysis of the test score of both groups

\begin{tabular}{|l|c|}
\hline Difference in mean & $\mathbf{3 . 0 0}$ \\
\hline Standard error & 1.348 \\
\hline 95\% confidence interval & 0.2378 to 5.7622 \\
\hline t- statistics & 2.225 \\
\hline DF & 28 \\
\hline Significance level & $\mathrm{P}=0.034$ \\
\hline
\end{tabular}

At $95 \%$ confidence interval $\mathrm{P}$ value $<0.05$ is considered significant

Table 3: Questionnaire and responses

\begin{tabular}{|c|l|c|c|c|c|}
\hline No. & Question & $\begin{array}{c}\text { Strongly } \\
\text { agree }\end{array}$ & Agree & $\begin{array}{c}\text { Disagree } \\
\text { Strongly } \\
\text { disagree }\end{array}$ \\
\hline 1 & Orientation of structures is better learnt while dissecting & 59 & 54 & 31 & 6 \\
$4 \%$ & $39 \%$ & $36 \%$ & $20 \%$ & 22 & 10 \\
\hline 2 & Consistency of Structures are appreciated better in dissection. & $39.5 \%$ & $38.6 \%$ & $14 \%$ & $6 \%$ \\
\hline 3 & Dissection helps students to learn to respect the dead. & 82 & 58 & 8 & 2 \\
\end{tabular}




\begin{tabular}{|c|c|c|c|c|c|}
\hline No. & Question & $\begin{array}{l}\text { Strongly } \\
\text { agree }\end{array}$ & Agree & Disagree & $\begin{array}{l}\text { Strongly } \\
\text { disagree }\end{array}$ \\
\hline 4 & Everyone is able to participate during dissection. & $\begin{array}{c}58 \\
38.6 \%\end{array}$ & $\begin{array}{c}66 \\
44 \%\end{array}$ & $\begin{array}{c}19 \\
12.6 \%\end{array}$ & $\begin{array}{c}7 \\
4.5 \%\end{array}$ \\
\hline 5 & $\begin{array}{l}\text { Visual memory following a dissection is better than } \\
\text { demonstration. }\end{array}$ & $\begin{array}{c}71 \\
47 \%\end{array}$ & $\begin{array}{c}60 \\
40 \%\end{array}$ & $\begin{array}{c}14 \\
9.3 \%\end{array}$ & $\begin{array}{c}5 \\
3.6 \%\end{array}$ \\
\hline 6 & $\begin{array}{l}\text { Chances of altering the normal anatomy and damage to structures } \\
\text { and thus enable to identify important structures - happens in } \\
\text { dissection. }\end{array}$ & $\begin{array}{c}29 \\
19.3 \%\end{array}$ & $\begin{array}{c}38 \\
25.33 \%\end{array}$ & $\begin{array}{c}49 \\
32.6 \%\end{array}$ & $\begin{array}{c}34 \\
22.6 \%\end{array}$ \\
\hline 7 & $\begin{array}{l}\text { Active participation is more in dissection, students work as a } \\
\text { team }\end{array}$ & $\begin{array}{c}41 \\
27 \%\end{array}$ & $\begin{array}{c}83 \\
54.5 \%\end{array}$ & $\begin{array}{c}21 \\
13.8 \%\end{array}$ & $\begin{array}{c}5 \\
3.6 \%\end{array}$ \\
\hline 8 & $\begin{array}{l}\text { Health hazards and injury risks to medical students are more with } \\
\text { dissection. }\end{array}$ & $\begin{array}{c}33 \\
22 \%\end{array}$ & $\begin{array}{c}23 \\
15.3 \%\end{array}$ & $\begin{array}{c}47 \\
31.3 \%\end{array}$ & $\begin{array}{c}47 \\
31.3 \%\end{array}$ \\
\hline 9 & $\begin{array}{l}\text { Dissection helps the student to learn how to use basic surgical } \\
\text { instruments. }\end{array}$ & $\begin{array}{c}56 \\
37.3 \%\end{array}$ & $\begin{array}{c}58 \\
38.5 \%\end{array}$ & $\begin{array}{c}23 \\
15.3 \%\end{array}$ & $\begin{array}{c}13 \\
8.6 \%\end{array}$ \\
\hline 10 & Dissecting is an useful tool for learning Anatomy & 59 & 49 & 34 & 8 \\
\hline
\end{tabular}

\section{Comparison of Marks of group A \& B}

30

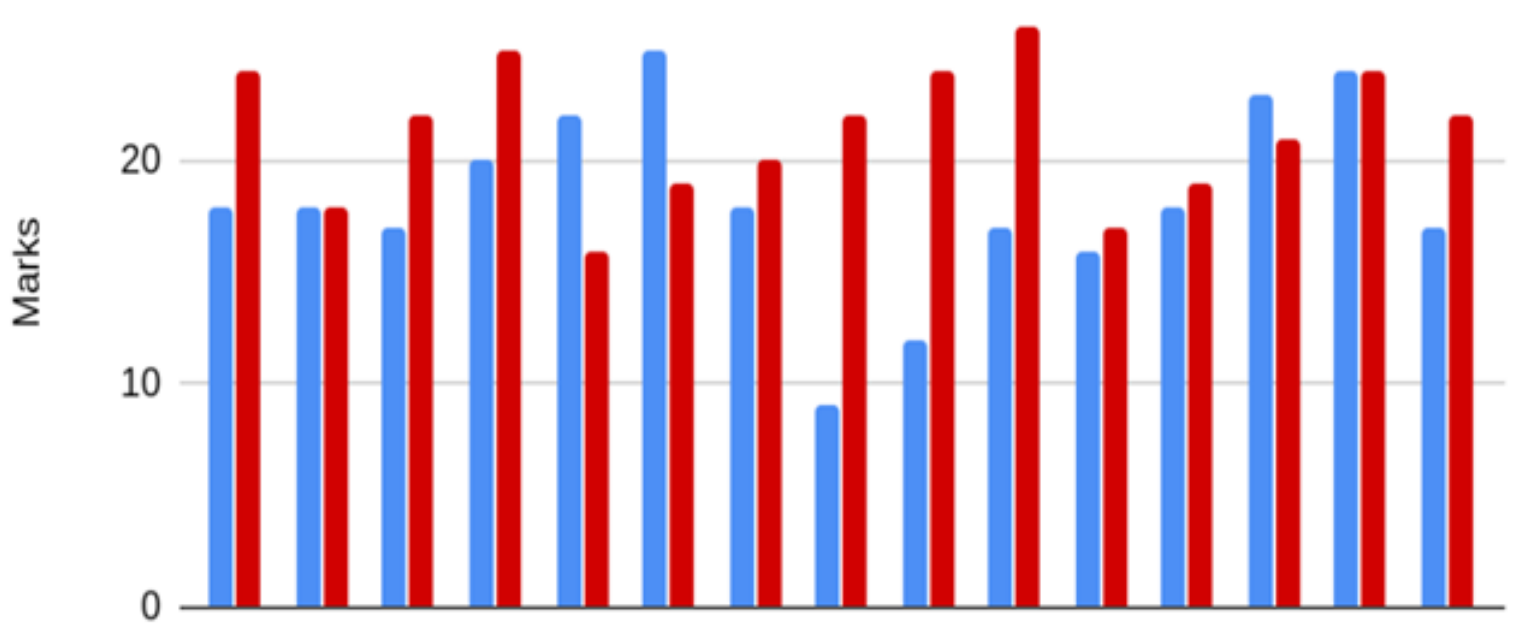

Students

Fig 1: Marks obtained by group A and group B students in spot identification test.

Blue - Group A, Red - Group B 


\section{BLUE - Group A, RED - Group B}

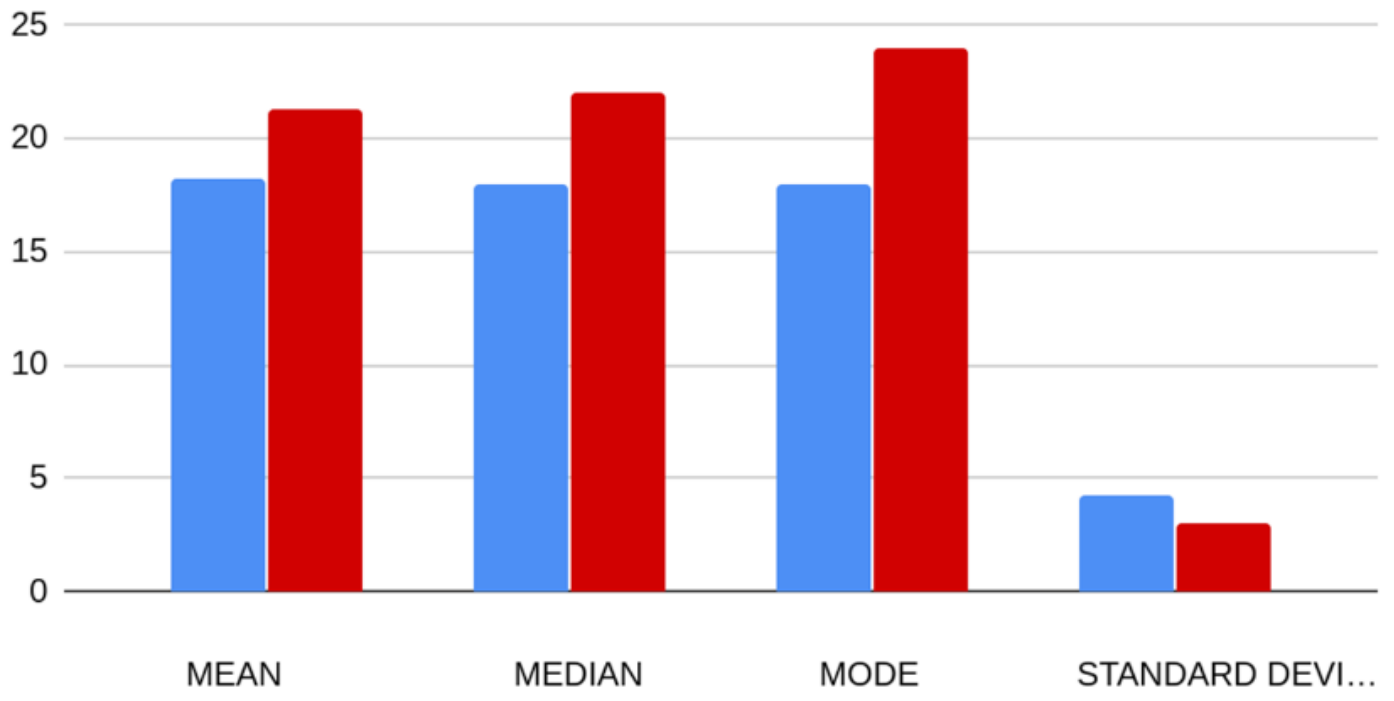

Fig. 2: Shows the percentage analysis of each response for each question

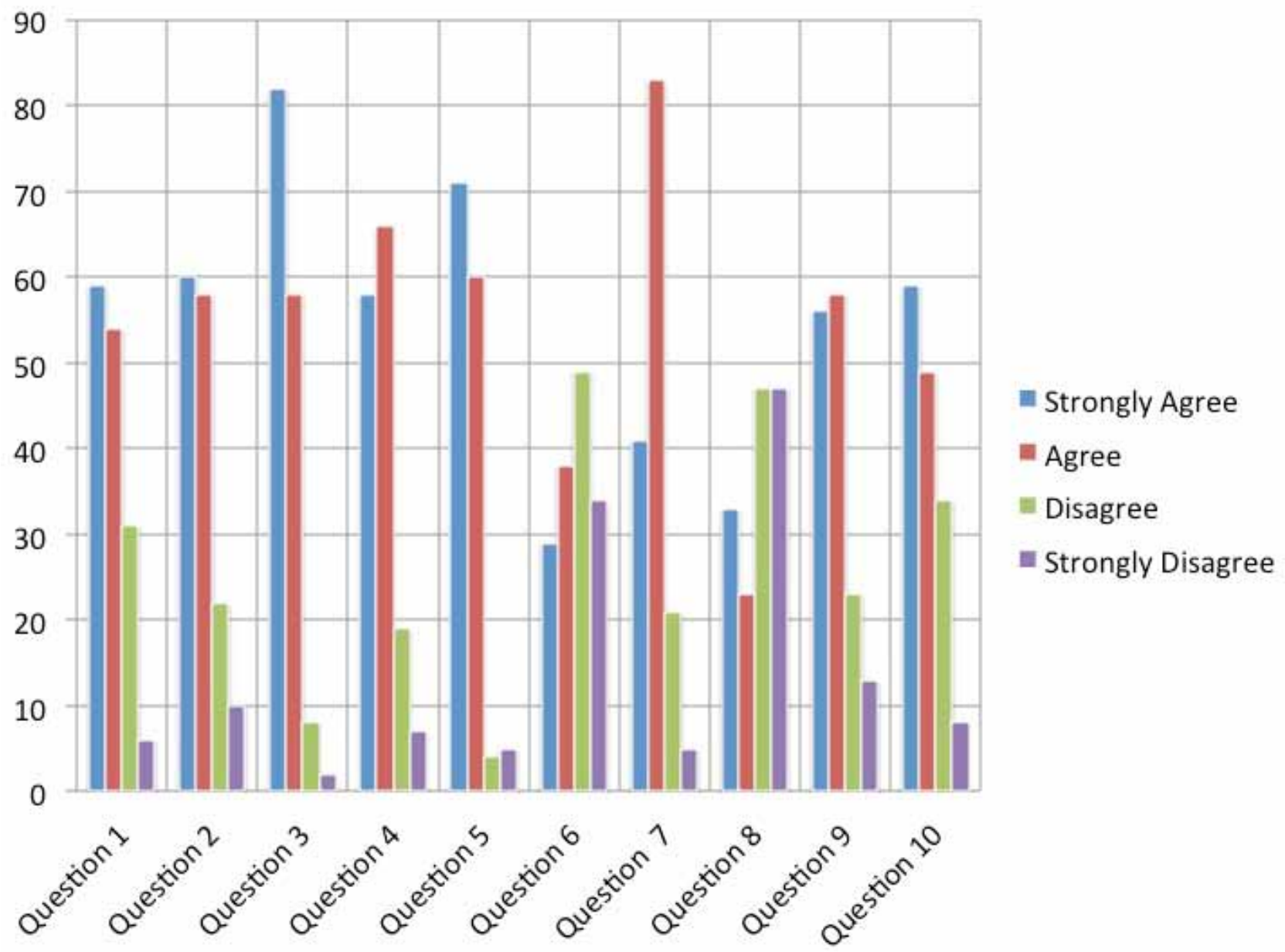

Fig. 3: Responses of the questionnaire is plotted 


\section{Discussion}

This cross sectional study conducted in two parts first part was to analyze the performance of first year MBBS students to two different pedagogical approach of teaching and learning gross Anatomy which clearly showed a significantly better performance of student taught by prosection technique and the second part of the study which was a survey conducted on final year students with a questionnaire which clearly showed final year students preferred dissection. In 2004 a study was conducted to consider the arguments related on use of cadavers for teaching Anatomy and to put forward the rationale in removing cadaveric dissection from a new medical school. They developed a curriculum design, assessment and evaluation process based on imaging, clinical skills and living anatomy for teaching Anatomy to first year students. ${ }^{15}$

In another review paper it is seen that Africa and USA are the leading areas where medical schools are offering cadaveric dissection. In Canada several medical schools have retained compulsory cadaveric dissection in their undergraduate program. In Asia data suggest India has continued teaching anatomy with cadaveric dissection. In European countries and Australia cadaveric dissection is not rampantly used. Many medical schools in UK and Australia are offering optional cadaveric dissection for undergraduate students. ${ }^{10,11,12 .}$

In a another similar study conducted by Nnodim $\mathrm{J}$ $\mathrm{O}$ et al on two matched group of preclinical students the students belonging to the group taught by experimental prosection technique performed better in the practical exam and multiple choice question test and difference was statistically significant. ${ }^{2}$ Present study too has a very similar result and difference inperformance of the two groups is statistically significant $\mathrm{p}$ value 0.034 .

A questionnaire study conducted on first year medical students on their views on cadaveric dissection showed $76 \%$ of students are excited and most of them did not have fear of dead $65 \%$. $85 \%$ felt cadaveric dissection gives better result than only demonstration on prosected specimens and $70 \%$ wanted dissection to be continued in Anatomy. ${ }^{13}$. These findings are very similar to our present study where final year students preferred cadaveric dissection in Anatomy and most of them liked dissection classes during their first year. Table 3 \& Fig 3

Journal of Anatomical Record invited faculty of four prestigious medical schools of US to represent the changing views of cadaver teaching in Anatomy and usage of technology to replace cadaveric teaching. In that discussion Kimberly S Topp from University ofCalifornia brought out the concept of pre dissected specimens and bodies for teaching Anatomy in alternative to cadaveric dissection by students. Though diagrams, animations, digital simulations do provide idea about the anatomical structures they are oversimplified. Ruff an author from John Hopkins has the view that there is definitely a sense of curiosity and satisfaction in hands on dissection especially appreciating the variations and organs in each cadaver. The texture of the structures, variations, reality of the specimens can be well appreciated in prosected specimens too. ${ }^{14}$

Though students complained of horrifying thoughts, anorexia, nausea, loss of appetite, fainting attacks, eye irritation etc on exposure to cadavers and dissection in first few days of their exposure to cadaveric dissection still dissection and prosection are learning tools in Anatomy which cannot be substituted by other method. ${ }^{16}$

\section{Conclusion}

This study suggest that utilizing prosected specimens for pedagogical teaching of the gross anatomy of neck region seem to be advantageous for students in identifying structures in the practical spotter examination and score higher marks. The performance of the first year students was statistically better for group B students taught by the above method. On analysing the view point of final year students on cadaveric dissection using questions based on Likert scale it showed students preferred dissection during their first year while learning Anatomy. Thus keeping in mind the final year medical students view point and better performance of first year students taught by pedagogical approach using prosected specimens it is concluded that both traditional teaching using cadaveric dissection and teaching with prosectedspecimens should be done hand in hand. This study findings show that complete removal of cadaveric dissection from MBBS curriculum would not be welcomed by medical students and there is a need of cadaveric dissection according to the survey. Thus it is recommended that cadavers can be judiciously used for teaching specific regions of gross Anatomy and students should be encouraged to participate in dissection. Prosection should also be included as a pedagogical approach in teaching gross Anatomy for improving the performance of the students in examinations. 
Ethical clearance obtained from institutional ethical committee prior to the study.

\section{Conflict of Interest: None}

Funding: Minimal self.

\section{References}

1. Mulu A., Tegabu D. Medical students' attitudinal changes towards cadaver dissection: A longitudinal study. Ethiop J Health Sci.2012; 22 (1):51-8.

2. Nnodim JO Learning human anatomy: by dissection or from prosections? Med Educ. Jul. 1990;24(4):389-95.

3. P. Finkelstein and L. H. Mathers, "Post-traumatic stress among medical students in the anatomy dissection laboratory," Clinical Anatomy. 1990;3 (3):219-226,

4. Williams SR1, Thompson KL2, Notebaert AJ1, Sinning AR1. Anat Sci Educ. 2019;12(2):173180. Prosection or Dissection: Which is Best for Teaching the Anatomy of the Hand and Foot?

5. Kimberly S Topp Prosection vs. Dissection, the Debate Continues: Rebuttal to Granger THE ANATOMICAL RECORD (PART B: NEW ANAT 2004;281B:12-14.

6. M., Kernick, E.T., Beck Dallaghan, G.L. et al. ADissection Versus Prosection: a Comparison of Laboratory Practical Examinations, Med.Sci. Educ.2019.https://doi.org/10.1007/s40670-01900839-6

7. B. Temkin, E. Acosta, A. Malvankar, et.al. "An interactive three-dimensional virtual body structures system for anatomical training over the internet," Clinical Anatomy, 2006;19(3):267-274.

8. J. S. Park, M. S. Chung, S. B. Hwang, B.-S.
Shin and H. S. Park, "Visible Korean human: its techniques and applications," Clinical Anatomy. 2006; 19(3):216-224.

9. S.-X. Zhang, P.-A. Heng and Z.-J. Liu, "Chinese visible human project," Clinical Anatomy,2006; 19 (3):204-215

10. Gangata $\mathrm{H}, \mathrm{Ntaba} \mathrm{P}, \mathrm{Akol} \mathrm{P}$, et al: The relianceon unclaimed cadavers for anatomical teaching by medical schools in Africa. Anat Sci Educ. 2010;3:174-183

11. Drake RL, McBride JM, Lachman Net al: Medical education in the anatomical sciences: the winds of change continue to blow. AnatSci Educ 2009;2:253-259.

12. Grant K: Dissection debate: why are medical schools cutting back on cadavers? $2014 \mathrm{http}: / /$ www.theglobeandmail.com/life/health-andfitness/ health/dissection-debate-why-aremedical-schoolscutting-back-on-cadavers/article $18296300 /$ (accessed 15 December2014).

13. Abha Bharathwaj, Mohammed Aman. Cadaveric Dissection- Its importance and students Response: A questionnaire study. International journal of Scientific Study 2017;5(5):252-55.

14. Der Bedrosian J: First-year medical students still rely on cadavers to learn anatomy. Johns Hopkins Magazine, Johns Hopkins University, 2016 https:// hub.jhu.edu/magazine/2016/winter/cadaversanatomy-medicalschool.

15. John C McLachlan, John Bligh, Paul Bradley et.al. Teaching Anatomy without cadavers. Medical education. 2004;38(4): 418-24.

16. Sunil Oza, Subhash Gujar, Jaidev Singh Shekhawat Attitude and responses of medical students towards cadaveric Anatomy. Int Jour of Scientific Research 2017;6(10): 717-718. 